\title{
Creativity in Teaching and Teaching for Creativity in Engineering and Science in Higher Education-Revisiting Vygotsky's Psychology of Art
}

\author{
Lucy Lunevich \\ School of Engineering, RMIT University, Melbourne, Australia \\ Email: lucy.lunevich@rmit.edu.au,llunevich@yahoo.co.nz
}

How to cite this paper: Lunevich, L. (2021). Creativity in Teaching and Teaching for Creativity in Engineering and Science in Higher Education-Revisiting Vygotsky's Psychology of Art. Creative Education, 12, 1445-1457.

https://doi.org/10.4236/ce.2021.127110

Received: June 4, 2021

Accepted: July 5, 2021

Published: July 8, 2021

Copyright (อ 2021 by author(s) and Scientific Research Publishing Inc. This work is licensed under the Creative Commons Attribution International License (CC BY 4.0).

http://creativecommons.org/licenses/by/4.0/

(c) (i) Open Access

\begin{abstract}
The article presents observational research conducted over four years which showed that creativity can be enhanced in all students using a variety of teaching methods and strategies. Strategies recommended promoting creativity including engaging students with activities that they enjoy and find intrinsically, encouraging students to verbally present and discuss their ideas with others, and providing opportunities for students to develop arguments based on evidence. Students should be encouraged to value empirical evidence and relevant knowledge and ideas, identify and address obstacles, learn about the lives and contributions of creative individuals throughout history, collaborate with others, take intellectual risks, and learn from mistakes in order to develop cognitive skills and self-efficacy. The research outlined here demonstrated that teaching critical analysis of art stimulated creativity in learners by facilitating emotional connections with the environment, encouraging a more holistic understanding of artworks and the creative processes behind them, and stimulating creative thinking skills and orientations that facilitated the development of intellectual potential.
\end{abstract}

\section{Keywords}

Creativity, Creative Pedagogy, Creative Teaching, Emotional Connection, Intrinsic Motivation, Critical Thinking, Problem Solving Skills

\section{Introduction}

This paper presents research conducted at the National Gallery of Victoria in Melbourne into methods that may facilitate students' greater engagement, 
learning, and creativity by exposing them to art installations, paintings, and modern and traditional art forms, and encouraging them to respond creatively to the stories behind the artworks. Vygotsky proposed that "creativity arises from any human activity that produces something new". Within his constructivist theory, the analysis of art has the potential to facilitate the development of higher cognitive abilities and provides an opportunity for collaborative learning when undertaken in group contexts. Vygotsky (2016) further proposed that many advances gained through human creativity and productivity have relied on collective creativity, in which small individual contributions combine to produce a greater outcome than individuals could have produced alone. Creativity of this kind should be encouraged among contemporary engineering and science students to support the problem-solving and critical thinking required to produce practical and theoretical solutions for complex modern problems.

Research indicates that modern workplaces demand critical thinking and creativity from employees, and these qualities are associated with higher productivity for employers and better work-life balance for employees (Bodrova \& Leong, 2007; Skills, 2011; Brody, 2000). Employees who can process large amounts of disparate information and apply critical thinking to problem-solve, including scientists and engineers, represent a competitive advantage for businesses. In addition, these abilities are likely to extend the lifespans of businesses and increase their organisational capacity to recruit and retain more highly-skilled employees. Critically, creative thinking is teachable, and the work of learning to think creatively is carried forward to be applied by learners across their later work (Karpov, 2014). That is, the work of learning creativity leads to the development of learners' creative abilities, which are then applied in the workplace (Vygostky, 2016). There is a consensus among scientists and scientist educators that scientific knowledge is the product of creative thinking (Marshall \& Batten, 2003). Thus, the demand for greater creativity in education is due not only to its recognised pedagogical effectiveness but also to the demands of the global economy for flexibility and adaptation to deliver innovation and competitiveness (Marshall \& Batten, 2003; Stanley, 1991). However, empirical evidence has shown that there is a lack of appreciation of the importance of creative thinking among undergraduate engineering and science students (Wadaani, 2015). This paper synthesizes recent research that demonstrates how teaching creativity can facilitate human development and self-actualisation for all students (Wadaani, 2015; Sternberg, 1985). The main goal of this research was to investigate the contribution of teaching for creativity to students' capabilities and intellectual potential (Wadaani, 2015; Lloyd, 2010; Cattell, 1963), and provide evidence to inform higher education teaching practices in science and engineering.

According to Sternberg and Kaufman (1998) and Sternberg and Lubart (1991), students' potential abilities will not be developed if teaching and evaluation systems undervalue creative, analytical, and practical abilities. Teaching 
should include skills-based and informational content but should also include explicit instruction in strategies for the critical analysis and evaluation of received knowledge. As such, teaching should encourage and nurture creativity in diverse forms and facilitate the overall development of students to realise their full cognitive capacities. Sternberg $(1985,2006)$ explained that "teaching for creative as well as analytical and practical thinking combined enables students to capitalise on their strengths and to correct or to compensate for their weaknesses in order to be successfully intelligent individuals" (Treffinger, 1988; Torrance, 1995).

Similarly, Vygotskian theorists propose that children's development is a process that depends on adult mediation (Vygostky, 2016; Karpov, 2014). As such, children will not develop to their full cognitive potential if teachers do not effectively scaffold their learning of skills and knowledge. The development of new interests and motivations in response to adult prompts leads students to engage with novel activities. Furthermore, the development of students' cognitive abilities-from their earliest developmental milestones to more advanced mental processes such as those needed for creativity-is proposed to rely on the acquisition, mastery, and internalisation of psychological tools that are modelled by adults and more advanced peers, and whose learning is scaffolded by teachers. According to Vygotskian theory (Karpov, 2014), the cultural experiences shared with students through mediation or teaching practice are their "cultural heredity", and these experiences are not available outside of adult teachers. However, the teaching of science and engineering rarely includes teaching creativity in this way or teaching through creative arts. Therefore, this paper presents research conducted at the National Gallery of Victoria in Melbourne into methods that may facilitate greater engagement, as well as enhance learning and creativity, by exposing students to art installations, paintings, and modern and traditional art forms, and encouraging them to respond creatively to the stories behind the artworks.

\section{Art and Creativity in Teaching}

To better understand the importance of creativity and creative arts for every individual, one must consider the significance art would acquire if this interpretation is correct. What is the relationship between aesthetic responses and other human behaviours? From a Vygotskian perspective, the function of art is to "infect" us with the emotions experienced by others, including through the stories behind the art (Karpov, 2014). Tolstoy proposed that "the activity of art is based on the capacity of people to infect others with their own emotions and to be infected by the emotion of others". Thus, observing art can lead us to discover, through imagination, a broader range of human experiences and knowledge than we could otherwise experience as individuals.

What connects teaching creative arts and teaching for creativity? They both provide learners with an emotional education. Following Tolstoy, teaching crea- 
tivity involves not only imparting specific content knowledge and rational analysis, but also involves scaffolding students' emotional and creative responses (Vygostky, 2016). Karpov (2014) suggested that creativity is at the heart of effective teaching itself and is vital to teaching in every subject area. They also proposed that learners need rich experiences to develop their creative skills and must be supported to use innovative approaches to enable this process of development. Therefore, teachers need to continuously reflect and incorporate learnings from their work into their teaching, as well as use the experiences of other teachers to develop fresh approaches to education that will inspire learners. Teachers need to move from flexibility in applying conventional methods to genuine creativity. This requires teachers to move out of their comfort zone of received knowledge into unknown territory to try new strategies and approaches (Davis, 2004; Lloyd, 2010).

There is a vast pedagogical literature on creativity that is relevant for university lecturers to apply in their teaching practice across subject areas (Woods, 1993, 1995). The role of creativity in teaching problem-solving strategies across a range of higher education contexts has been studied by several scholars, building on the work of (Marshall \& Batten, 2003). For example, Woods $(1990,1993)$ argued that creativity is associated with the generation of unexpected responses through novel connections and associations between existing pieces of information and knowledge. This work is relevant for teaching science and engineering students to become effective problem-solvers in the modern workplace.

\subsection{Teaching for Creativity Science and Engineering Students}

Creativity has been described as a multifaceted phenomenon that can be developed for all students in different areas (Wadaani, 2015: p. 6). Davis (2004) stated that "creativity can be expressed in a nearly infinite number of ways in human behaviour and has its origins in several components of individual and social experience". Rozesahegyi (2019) and Denscombe (2017) argued that creativity is an important component of problem-solving, healthy social and emotional well-being, and scholastic and workplace success. Therefore, teachers should not only teach creatively, but also teach for creativity, thereby motivating students to think effectively and become creative learners who can make informed and considered decisions and choices in novel situations (Sternberg, 2006; Lloyd, 2010; Wadaani, 2015; Brinkman, 2010). As stated by Tanggaard (2013), "societies that do not make every effort to assure that the potential talents of young people are utilised are losing their most valuable natural resource; human capital" (Wadaani, 2015). Thus, teaching creativity is relevant across all subject areas, all disciplines, and for all students.

Research has also indicated that digital businesses in particular demand creative individuals who can solve their clients' problems and provide increased value for employers (Carroll, 1993; Brinkman, 2010). In business contexts, value is added by workers who can solve problems efficiently and demonstrate imme- 
diate commercial benefits for clients and employers through these solutions (Carroll, 1993). However, there is empirical evidence that many engineering and science students do not appreciate the relevance of creative thinking to their disciplines. Furthermore, teaching in science and engineering subjects can be dry and provide limited encouragement for students to analyse and apply content knowledge creatively.

Sternberg et al. (1997) argued that creativity is not a learning objective to be achieved and measured, but an approach to thinking that all individuals should continue developing to the highest level possible. Teaching for creativity is not a teaching method, but a teaching philosophy designed to facilitate the continued development of students (Wadaani, 2015). Through this approach to teaching, multiple teaching strategies and methods can be modified or generated to lead students to develop their creativity in different contexts and at different levels. She and other scholars contend that teachers should teach for creativity as a complex capacity that can change and develop with infinite potential (Wadaani, 2015; Jeffrey \& Craft, 2004). Most teaching methods can be adapted to develop student creativity and provide positive experiences for students within a philosophical framework of teaching for creativity.

When teachers understand their roles in constructivist terms as a facilitator of optimal human development and conceptualise creativity as "the hub of real achievement," they can continue to learn to teach for creativity by engaging in professional development (Wadaani, 2015). Teachers can practice novel teaching styles that complement the teaching methods they already use to create an environment that facilitates creativity. Teachers may also use teaching techniques designed to enhance creativity in general, or to foster and scaffold the development of certain aspects of creativity, such as collective creativity (Falk \& Szech, 2013; Wadaani, 2015). Here, teachers might benefit from taking risks and trying new strategies to evaluate what works.

\subsection{Critical Thinking and Problem-Solving Skills}

Critical thinking has been described as the ability to engage in reflective and independent thinking (Skills, 2011), and has been the subject of debate and theorising from the time of Plato and Socrates into the contemporary era. For example, critical thinking is often discussed in relation to students' ability to evaluate information found online (Karpov, 2014; Beghetto \& Kaufman, 2007). Critical thinking requires students to use their ability to reason. Karpov (2014) defined critical thinking as the intellectually-disciplined process of actively and skilfully conceptualising, applying, analysing, synthesising, and evaluating information gathered from, or generated by, observation, experience, reflection, reasoning, or communication, grounded in reality. Thus, critical thinking requires students to become active learners rather than passive recipients of information. In practice, this entails actively engaging with class conversations, being motivated to contribute and ask questions, and pursuing additional learning outside of classes. 
Critical thinkers rigorously question ideas and assumptions rather than accepting them at face value. They seek to evaluate whether ideas, arguments and findings are biased or incomplete, and are open to challenges to accepted thinking. Critical thinkers will identify, analyse and solve problems systematically rather than by intuition or instinct, or by deferring to authority. Students who master critical thinking will be equipped to solve emerging business problems once they are employed.

\section{Observation in Education Research}

As a method for education research, observation offers a way to analyse human behaviour and thinking in real-world contexts. Gathering useful observational data over time requires considerable methodological and ethical deliberation. For educators, carefully planned and rigorous observational protocols are recommended to usefully inform their professional practice. According to Rozesahegyi (2019) and Cohen et al. (2018), analysing classroom observations is invaluable for comprehending and evaluating learners' knowledge, skills, curiosity, and cognitive development. In addition, the observation of teaching practitioners by other practitioners as a part of training and mentoring is invaluable for improving teachers' professional practice.

When education researchers conduct an observational research study, the observations must be planned and follow specific protocols, and will be qualitatively and quantitatively different to everyday observing and perceiving in social contexts (Rozesahegyi, 2019). Cohen et al. (2018) and Rozesahegyi (2019) pointed out that observational research involves "more than just looking, and requires systematic observation of the number and type of relevant events, behaviours, setting, artefacts, and routines". Observational research requires training and practice.

In education research, observation may include the physical environment and organisational context, classroom organisation, individual or group activities, allocation of teaching assistances in lesson time, the nature of interactions between participants, and the complexity of problems students are asked to resolve. Observations may also be made of pedagogical characteristics of the research setting, such as the teaching strategies and resources adopted (Rozesahegyi, 2019). Observational research was conducted with child learners in primary schools from 1990 that initially focused on the creativity of the teacher and the nature of creative teaching (Weisberg, 1999). More recent research has focused on the effects of creative teaching on learners to evaluate its effectiveness by comparing the creativity they bring to the learning context with the creativity they were encouraged to develop through creative teaching activities (Sternberg, 2004; Sternberg et al., 2008; Weisberg, 1999; Woods, 1990, 1993, 1995). This paper takes its approach from these long-term ethnographic studies carried out in creative classes to investigate the relationship between teaching art and creativity, and teaching for creativity in education. 
In this research project, the research questions were "how does positive emotional engagement of students influence the quality of learning?" and "does this pedagogical approach facilitate creativity in students with limited experience of art galleries?". Once an observational approach was chosen as an appropriate method of gathering data, research planning addressed practical issues including decisions about the role of the observer, how the processes of observation might influence the behaviour of those being observed, how the observation data will be recorded, analysed and interpreted, and whether the observation method is ethical and morally sound. A further question was included for determining the specific focus of observations.

Structured or "systematic" observational methods were used in this research (Rozesahegyi, 2019). Observational data were recorded in defined categories that were designed to capture relevant behaviours, events, and activities. The researcher aimed to log the number and types of behaviours, events, and activities that allowed comparisons to be made between participants, as well as frequencies, patterns, and trends to be noted and evaluated (Rozesahegyi, 2019; Cohen, Manion, \& Morrison, 2018). Observations included the gallery setting, student behaviour, and students' verbal responses to the artworks.

\section{Involvement of Students in Education Enquiry}

Involvement of students in education enquiry has been advocated for many years. Rozesahegyi (2019) suggested that significant knowledge gains result when children's active participation in the research process is deliberately solicited and when their perspectives, views, and feelings are accepted as genuine, valid evidence. Rozesahegyi (2019) and Treffinger et al. (2012) both have argued that students have valuable perspectives to share about many issues, and that students' participation can make essential contributions to longer-lasting, longitudinal research. It would be beneficial to evaluate how the age, experience, and/or culture of students may bring greater variation.

Students were involved in this research in three ways. Over 200 students completed a four-page questionnaire which asked about their attitudes towards difficult versus easy academic tasks, and how creativity could help them to solve problems. In addition, students took part in small-group interviews, and individual questions were asked to all students in the gallery across various installations to gain better understanding their interpretation of the art form, such as "What feelings does this stimulate?". It has been observed that the less experienced a student was with art, the more creative and innovative ideas they generated.

Features of the students' relationship to the investigation became particularly clear in the interviews. These interviews did not follow a consistent, formal, question-and-answer structure but were organized more around themes, exploring experiences and beliefs in a discussion style. For the most part, the participating students were self-assured enough to take control over the interview 
agenda, expressing opinions, spontaneously recollecting memorable occurrences, and even setting out new directions for dialogue. Although nothing inappropriate was said, the fact that the students were away from the lecturers may also have helped to promote active and honest discussion.

The fact that the discussions were carried out in groups of three, four or five students, not individually, seemed to add to the value of the methodology. Fellow students, more than lecturers, stimulated judgments and reflections in each other.

\section{Research Methodology}

This observational study investigated teaching for creativity in lecture tours conducted with Masters students from RMIT University, College of Science, Health and Engineering, at the National Gallery of Victoria (NGV) in Melbourne over four years from 2018 to 2021. The program aimed to increase the engagement of international students. Participating students were ages 23 - 53 years, and approximately 30\% female and 70\% male. Students in this program included international students from China, India, Indonesia, Malesia, Norway, Turkey, Saudi Arabia, and Middle Eastern countries. Lecture tours were designed in collaboration with an NGV Curator.

Observational data were collected by the author, who delivered the program with NGV curators. Observational data collection focused on student behaviour and students' responses to questions during lecture-tour activities that were designed to engage students with the chosen artworks and their backstories. Observational data were collected of learners' unprompted expression of ideas and their participation in group activities. Students' emotional engagement with gallery installations was also noted. Individual students and student groups were asked to produce creative descriptions of unfamiliar artworks and to imagine the story behind the artwork's creation. A main objective of the lecture tours was to empower learners to take ownership of their learning and provide educational activities in a setting that would stimulate emotional expression, individual connection to the artwork, creative evaluation of the artwork, critical thinking, and imaginative thought.

\section{Ethics of Observation}

This brings us to a reflection on ethics. Ethics can involve the basic idea that "research should avoid causing harm, distress, anxiety, pain any other negative feeling to participants," or even that researchers should aspire "to conduct research that benefits participants in positive ways". Indeed, the unusualness, the specialness, perhaps the "group"-ness of the task, especially the interviews, seemed to be a stimulus and reward enough for the students in this research. The lending of self-esteem, as well as the educational benefits which might ultimately result from the study and their participation in it, was well-balanced with the advantages of their involvement to the researcher himself. The building of 
'rapport' is often put forward as best practice in any kind of research in which others are involved, most credibly perhaps by Baker (2006) in relation to social-work and police investigations.

Observation in the gallery raised its own ethical issues, particularly in relation to the researcher's relationship to the context being observed. Baker (2006) reminder is that the researcher should not challenge the accepted customs and value systems of the context of 'social ecology', not just for ethical reasons, but also so that data will reflect the real nature of the observed setting. Instead, the researcher should try to merge with these systems. Patton (2015) has similarly advised that the researcher not disturb the relationship between students and lecturers.

\section{Results}

Fifty percent of participating students had never previously been in an art gallery, $40 \%$ reported limited exposure to art history, and less than $10 \%$ of participating students had occasionally visited the gallery. Observation of students' ability to express their creative ideas in response to art installations in the NGV indicated that students engaged positively with the artworks, and their stories and were highly engaged when asked to express creative responses to complex questions posed by the lecturer and curator. For example, students engaged in animated discussion about their emotional responses to specific artworks. Many students offered multiple responses to the questions asked by the lecturer and tried to approach problems from different perspectives than those the lecturer had presented or considered.

All participating students demonstrated an ability to generate innovative responses, take ownership of the inquiry-based activities, offer varied solutions to questions posed by the lecturer and curator, and think outside the norm. Students also demonstrated an ability to generate and evaluate ideas quickly during the limited time available. In these activities, students demonstrated the development of a more holistic understanding of the artworks, and the creative processes behind them, through true creative thought. Consistent with Vygotsky's constructivist theory, collective creativity was also observed in group activities when individuals pooled and discussed their creative responses to develop more advanced ideas and understandings. These findings are consistent with observations from the long-term ethnographic studies of child learners in creative classes discussed above.

In the NGV lecture-tour classes, students showed appreciation for the creative environment. This was demonstrated through their expressions of positive emotion, and through their enthusiasm in discovery and experimentation when perceiving and critically analysing the artwork, technology, and design. The NGV installations provided a focus for intensive problem-solving activity and critical thought. Students worked through frustrations experienced in the challenging process of developing novel and creative solutions to questions. They also ex- 
pressed satisfaction in producing solutions and making conclusions based on critical analysis. Discussing the artworks with student peers provided an opportunity for students to express emotional responses and share those of their peers, facilitating collective creativity.

In addition, students were personally engaged with the artworks beyond the minimal requirements of lecture-tour participation. According to Patton (2015), ensuring the relevance of the pedagogy to learners will encourage their ownership of their engagement with learning, as the learning will be directly related to their intrinsic interests. The lecturers scaffolded students' learning by suggesting interpretive strategies for analysing art that effectively engaged the students. Students then acted creatively to apply these strategies appropriately. The optimal pedagogical relevance of the NGV lecture tours to learners was evident in the way learners took ownership of their experiences in the NGV.

These findings support the idea that lecturers should aim to creatively develop materials and approaches that encourage students' interests and motivate their learning. Jeffrey and Craft (2004) suggested that teachers need to make teaching and learning relevant and encourage ownership of learning by passing back control of the learning activities to the learner (Amabile, 1982, 1996a, 2001; Baer, 2010; Batey \& Furnham, 2006; Jeffrey \& Craft, 2004), and encourage innovation and critical thinking through emotional connections to the content. In the lecture-tour, this was achieved through providing the opportunity for students to engage with artworks and their stories, to explore their preferences between the artworks on display, and to pursue critical thinking based on their perceptions of the artworks. Having control over learning provides learners with the opportunity to solve problems independently using their preferred strategies, and to innovate and express personal and developing ideas and feelings spontaneously in a supportive, collective context (Torrance, 1962, 1993, 1995; Treffinger, 1988, 1991).

One of the major characteristics of creativity is considering novel possibilities and exchanging ideas with others. Therefore, teaching for creativity should encourage learners to take control to facilitate innovation. In this research, learners were stimulated to think creatively by providing opportunities for emotional connection to artwork in an environment that supported expressions of individual and collective creative thinking in response to the subject material. Lecturers were available to listen and reinforce learners' creativity and created a supportive environment for learners to think creatively, solve problems, analyse and question the art form, and communicate about the art and its stories with other learners. Importantly, learners were encouraged to discuss ideas and stimulate creativity in others. Students were prompted to evaluate their creative ideas in discussion with others and develop further ideas collectively. These activities included teachers and students as co-participants, supporting research by Amabilie (1996a, 1996b, 1983) which suggested that being encouraged to pose questions, [and] identify problems and issues together, with the opportunity to 
debate and discuss their "thinking", [takes] the learner into the heart of both the teaching and learning process as a co-participant (Cohen, Manion, \& Morrison, 2018). In this way, the lecture tours effectively encouraged students to take ownership of their learning and to practice creative thinking skills collectively.

\section{Conclusion}

The observations reported in this research highlight that, regardless of age, cultural background, or gender, all students engaged emotionally with the artworks and their stories. The positive impact of teaching for creativity was demonstrated through learners expressing pleasure in experiencing the spark of creativity, exploring creativity by evaluating their own and others' ideas, and collectively developing new responses. The research outlined here shows that creative teaching of the arts stimulates creativity in learners by facilitating emotional connections with the artworks and the stories of their creation that engage learners. Importantly, these activities also stimulated intrinsically motivated engagement in activities that provided students with opportunities to develop creative thinking skills that could then be applied in the future across a range of individual and collective problem-solving contexts.

\section{Conflicts of Interest}

The author declares no conflicts of interest regarding the publication of this paper.

\section{References}

Amabile, T. (1982). A Consensual Assessment Technique. Journal of Personality and Social Psychology, 43, 997-1013. https://content.apa.org/doi/10.1037/0022-3514.43.5.997

Amabile, T. (1996a). Assessing the Work Environment for Creativity. Academy of Management Journal, 39, 1154-1184.

Amabile, T. (1996b). Creativity in Context: Update to the Social Psychology of Creativity (pp. 320-334). New York: Routledge.

Amabile, T. (2001). Beyond Talent: John Irving and the Passionate Craft of Creativity. American Psychologist, 56, 333-336. https://doi.apa.org/doi/10.1037/0003-066X.56.4.333

Amabilie, T. (1983). The Social Psychology of Creativity: A Component Conceptualisation. Jounral of Personality and Social Psychology, 45, 357-376. https://content.apa.org/doi/10.1037/0022-3514.45.2.357

Baer, J. G. (2010). Teaching for Creativity in an Era of Content Standards and Accountability. In R. A. Beghetto, \& J. C. Kaufman (Eds.), Nurturing Creativity in the Classroom (pp. 6-19). Cambridge: Cambridge University Press. https://doi.org/10.1017/CBO9780511781629.003

Baker, L. M. (2006) Observation: A Complex Research Method. Library Trends, 55, 171-189. https://doi.org/10.1353/lib.2006.0045

Batey, M. F., \& Furnham, A. (2006). Creativity, Intelligence and Personality: A Critical Review of the Scattered Literature. Genetic, Social, and General Psychology Monographs, 132, 355-429. https://doi.org/10.3200/MONO.132.4.355-430 
Beghetto, R. A., \& Kaufman, J. C. (2007). Toward a Broader Conception of Creativity: A Case for Mini-C Creativity. Psychology of Aesthetics, Creativity, and the Arts, 1, 73-79. https://doi.apa.org/doi/10.1037/1931-3896.1.2.73

Bodrova E., \& Leong, D. J. (2007). Tools of the Mind: The Vygotskian Approach to Early Childhood Education. Columbus, OH: Merrill/Prentice Hall.

Brinkman, D. (2010). Teaching Creatively and Teaching for Creativity. Arts Education Policy Review, 111, 48-50. https://doi.org/10.1080/10632910903455785

Brody, N. (2000). History of Theories and Measurements of Intelligence. In R. J. Sternberg (Ed.), Handbook of Intelligence (pp. 16-33). Cambridge: Cambridge University Press. https://doi.org/10.1017/CBO9780511807947.003

Carroll, J. B. (1993). Human Cognitive Abilities: A Survey of Factor-Analytic Studies. New York, NY: Cambridge University Press. https://doi.org/10.1017/CBO9780511571312

Cattell, R. B. (1963). Theory of Fluid and Crystallised Intelligence: A Critical Experiment. Jounral of Educational Psychology, 54, 1-22. https://doi.apa.org/doi/10.1037/h0046743

Cohen, L., Manion, L., \& Morrison, K. (2018). Research Methods in Education (8th ed.). London: Routledge. https://doi.org/10.4324/9781315456539

Davis, G. A. (2004). Creativity Is Forever (5th ed.). Dubuque, IA: Kendall Hunt Publishing.

Denscombe, M. (2017). The Good Research Guide: For Small-Scale Social Research Projects (3rd ed.). Maidenhead: Open University Press.

Falk, A., \& Szech, N. (2013). Morals and Markets. Journal of Science, 340, 707-711.

Jeffrey, B., \& Craft, A. (2004). Teaching Creatively and Teaching for Creativity: Distinctions and Relationships. Educational Studies, 30, 77-87.

https://doi.org/10.1080/0305569032000159750

Karpov, Y. V. (2014). Vygotsky for Educators. Cambridge: Cambridge University Press. https://doi.org/10.1017/CBO9781107588318

Lloyd, G. E. R. (2010). History and Human Nature: Cross-Cultural Universals and Cultural Relativities. Interdisciplinary Science Reviews, 35, 201-214.

https://doi.org/10.1179/030801810X12723585301318

Marshall, A., \& Batten, S. (2003). Ethical Issues in Cross-Cultural Research. Connections, 3, 139-151.

Patton, M. Q. (2015) Qualitative Research and Evaluation Methods: Integrating Theory and Practice (4th ed.). London: Sage.

Rozesahegyi, T. (2019). Observations. In M. Lambert (Ed.), Practical Research Methods in Education: An Early Researcher's Critical Guide (pp. 23-34). London: Routledge. https://doi.org/10.4324/9781351188395-3

Skills, T. P. (2011). Framework for 21st Century Learning (pp. 20-50). Washington DC: Partnership for 21st Century Learning.

Stanley, J. C. (1991). An Academic Model for Educating the Mathematically Talented. Gifted Child Quarterly, 35, 36-42. https://doi.org/10.1177\%2F001698629103500105

Sternberg, R. J. (1985). Beyond IQ: A Triarchic Theory of Human Intelligence. Cambridge: Cambridge University Press.

Sternberg, R. J. (2004). Teaching College Students That Creativity Is a Decision. Guidance \& Counseling, 19, 196-200.

Sternberg, R. J. (2006). The Nature of Creativity. Creativity Research Journal, 18, 87-98. https://doi.org/10.1207/s15326934crj1801 10 
Sternberg, R. J., \& Lubart, T. I. (1991). An Investment Theory of Creativity and Its Development. Human Development, 34, 1-34. https://doi.org/10.1159/000277029

Sternberg, R. J., \&. Kaufman, J. C. (1998). Human Abilities. Annual Review of Psycholo$g y, 49,479-502$. https://doi.org/10.1146/annurev.psych.49.1.479

Sternberg, R. J., Kaufman, J. C., \& Grigorenko, E. L. (2008). Applied Intelligence. Cambridge: Cambridge University Press. https://doi.org/10.1017/CBO9780511611445

Sternberg, R. J., O’Hara, L. A., \& Lubart, T. I. (1997). Creativity as Investment. California Management Review, 40, 8-21. https://doi.org/10.2307\%2F41165919

Tanggaard, L. (2013). The Sociomateriality of Creativity in Everyday Life. Culture \& Psychology, 19, 20-32. https://doi.org/10.1177\%2F1354067X12464987

Torrance, E. P. (1962). Guiding Creative Talent. Prentice-Hall, Inc. https://content.apa.org/doi/10.1037/13134-000

Torrance, E. P. (1995). Insights about Creativity: Questioned, Rejected, Ridiculed, Ignored. Educational Psychology Review, 7, 313-322. https://doi.org/10.1007/BF02213376

Torrance. E. P. (1993). Understanding Creativity: Where to Start? Psychological Inquiry, 4, 232-234. http://www.jstor.org/stable/1448974 https://doi.org/10.1207/s15327965pli0403 17

Treffinger, D. (1988). Components of Creativity: Another Look. Creative Learning, 2, 1-4.

Treffinger, D. (1991). Creative Productivity: Understanding Its Sources and Nurture. IIlinois Council for Gifted Journal, 10, 6-8.

Treffinger, D. S., Selby, E. C., \& Schoonover, P. F. (2012). Educating for Creativity and Innovation: A Comprehensive Guide for Research-Based Practice. Waco, TX: Prufrock Press.

Vygotsky, L. S. (2016). The Psychology of Art. Cambridge, Massachusetts, and London, England: The M.L.T Press.

Wadaani, M. (2015). Teaching for Creativity as Human Development towards Self-Actualization: The Essence of Authentic Learning and Optimal Growth for All Students. Creative Education, 6, 669-679. https://doi.org/10.4236/ce.2015.67067

Weisberg, R. (1999). Creativity and Knowledge. In R. Sternberg (Ed.), Handbook of Creativity (pp. 226-250). Cambridge: Cambridge University Press. https://doi.org/10.1017/CBO9780511807916.014

Woods, P. (1990). Teacher Skills and Strategies. London: Falmer Press.

Woods, P. (1993). Critical Events in Teaching and Learning. London: Falmer Press.

Woods, P. (1995). Creative Teachers in Primary Schools. Buckingham: Open University Press. 